\title{
ARTIKULASI KELAS BAWAH JAWA DALAM KUMPULAN PUISI PARA JENDERAL MARAH-MARAH KARYA WIJI THUKUL
}

\author{
Joko Santoso \\ FKIP Universitas Sarjanawiyata Tamansiswa \\ email: jokosantoso@ustjogja.ac.id
}

\begin{abstract}
Abstrak
Penelitian ini bertujuan mendeskripsikan artikulasi kelas bawah Jawa dalam kumpulan puisi Para Jenderal Marah-Marah karya Wiji Thukul. Penelitian ini menggunakan pendekatan teori Cultural Studies yang sekaligus menerapkan metode kajiannya dalam tiga level yaitu: epistemologis, politis, dan strategis. Hasil penelitian sebagai berikut. Pertama, negosiasi perempuan kelas bawah Jawa dengan tujuan mengacaukan posisi kultural laki-laki yang mendekati absolutisme. Kedua, terungkapnya sisi kultural laki-laki dari sisi yang lain, yang menunjukkan nilai-nilai yang bertolak belakang dengan nilai-nilai adiluhung yang melekat padanya dengan tujuan menimbulkan chaos, melawan mitos, dan membangun mitos baru bahwa laki-laki tidaklah sepenuhnya adiluhung dan atau bahkan mendekati absolutisme. Ketiga, terungkapnya sistem yang secara struktural diatur sedemikian rupa oleh narasi besar atau negara yang belum berpihak kepada kepentingan rakyat kelas bawah.
\end{abstract}

Kata kunci: artikulasi, kelas bawah Jawa, Cultural Studies, Wiji Thukul

\section{THE ARTICULATION OF THE LOWER CLASS JAVANESE PEOPLE IN WIJI THUKUL'S POETRY COLLECTION PARA JENDERAL MARAH-MARAH}

\begin{abstract}
This study aimed to describe the articulation of the lower class Javanese people in Wiji Thukul's poetry collection Para Jenderal Marah-Marah. It used the Cultural Studies approach and simultaneously applied it in three levels, i.e. epistemological, political, and strategic levels. The results of the study are as follows. First, there are negotiations of the lower class Javanese women with the aim of disrupting men' cultural position which nearly reaches absolutism. Second, there is a disclosure of the other side of men's culture, which shows values contrary to the inherent noble values with the aim of causing chaos, confronting myths, and building new myths that men are not entirely noble and or even close to absolutism. Third, there is a disclosure of a system that is structurally organized in such a way by a great narrative or a state that has not been in favor of the lower class people's interests.
\end{abstract}

Keywords: articulation, lower class Javanese people, Cultural Studies, Wiji Thukul

Artikulasi Kelas Bawah Jawa dalam Kumpulan Puisi Para Jenderal Marah-Marah Karya Wiji Thukul 


\section{PENDAHULUAN}

Representasi terhadap kelas bawah Jawa tidak pernah mendapatkan posisi yang penting dalam sastra Indonesia modern. Kisah mengenai kelas bawah Jawa yang kemudian 'naik kelas' menjadi priayi (kelas atas) pernah digambarkan Umar Kayam, dengan tokoh bernama Lantip dalam novel Para Priayi walaupun diikuti dengan bermacam persoalan pelik sesudahnya. Sebaliknya, dalam novel Pengakuan Pariyem, karya Linus Suryadi A.G., tokoh Pariyem tidak digambarkan 'naik kelas' seperti Lantip, tetapi sebagai sosok yang 'nrima' (pasrah). Dua representasi tersebut memberi gambaran bahwa kelas bawah Jawa belum memiliki daya tawar atau negosiasi budaya secara seimbang.

Selain itu, dalam budaya Jawa hierarki kelas kelihatan sangat menonjol seperti pernah digambarkan oleh Clifford Geertz dengan membagi masyarakat Jawa dalam tiga golongan: priayi, santri, dan abangan. Golongan atau kelas paling bawah yaitu abangan barangkali kelas yang sama sekali tidak memiliki daya tawar atau negoisasi dalam struktur kulturalnya. Meskipun daya tawar atau negosiasi kultural ini bukan perkara mudah, tetapi bukan berarti pula sebagai kemustahilan.

Berbeda dengan Umar Kayam, ataupun Linus Suryadi A.G., representasi kelas bawah Jawa digambarkan memiliki daya tawar atau negosiasi dalam puisi-puisi Wiji Thukul yang terkumpul dalam kumpulan puisi Para Jenderal Marah-Marah (2013). Masyarakat kelas bawah Jawa dalam puisipuisi Wiji Thukul merupakan representasi dari: bakul (pedagang) kecil, anak putus sekolah, sopir becak, pelacur, perempuan (wong wedok) domestik (yang merupakan ibu rumah tangga). Dalam representasinya,
Thukul memosisikan masyarakat kelas bawah tersebut sebagai golongan kelas bawah yang punya daya tawar atau negosiasi kultural. Mereka (golongan kelas bawah Jawa), setidaknya diberi ruang untuk bersuara atau berartikulasi untuk merespon hal-hal yang tidak seimbang termasuk berbagai jenis penindasan baik langsung, struktural, ataupun kultural.

Alasan memilih karya-karya Wiji Thukul sebagai objek penelitian (baik objek formal maupun material) adalah bahwa Wiji Thukul adalah salah satu dari 'sedikit' penyair yang baik dalam karya maupun di kehidupan nyata selalu menyuarakan semangat keadilan terutama pembelaan kaum proletar atau kelas bawah. Semangat itu terlihat dalam hampir semua puisinya. Namun, kelas bawah Jawa lebih jelas terlihat dalam kumpulan puisi Para Jenderal Marah-Marah daripada kumpulan puisi lainnya.

Daya tawar dan negosiasi yang artikulatif sejalan dengan prinsip Cultural Studies yang pertama kali lahir di Inggris (disebut dengan Lingkaran Birmingham). Stuart Hall merupakan tokoh sentral dari prinsip artikulasi ini. Stuart Hall memperkenalkan Cultural Studies (selanjutnya CS) dalam esainya yang terkenal berjudul " $\mathrm{Cul}$ tural Studies: Two Paradigms" pada 1980. Namun sebelum itu, pada 1970an, CS sudah diperkenalkan di Inggris, yaitu dikenal dengan Mazhab Birmingham, atau Lingkaran Birmingham 'Birmingham Schoo' (Milner, 2002; Belsey, 2003; McQuillan, 2003; Connell \& Hilton, 2015; Turner, 2014; Bennet, 2015; Ang, 2013), atau Centre for Contemporary Cultural Studies (CCCS) (1968-1979) (Stacey, 2015; Clarke, 2016). Stuart Hall sering disinonimkan dengan CS. Walaupun ia seorang pengajar dan 
kritikus, tetapi kontribusinya terhadap kehidupan masyarakat lebih besar ketimbang sebagai akademikus (Davis, 2004). Hall adalah seorang perintis kajian-kajian budaya yang terbuka terhadap berbagai teori yang berkembang di kalangan akademisi dan filosof. Ia keluar dari batasbatas perspektif kulturalisme yang dianut tokoh-tokoh perintis lainnya, dan dengan cepat mengakomodasi strukturalisme, semiotik, strukturalisme-marxis, teori hegemoni, teori pascastruktural, feminis, pascakolonialisme, dan pascamodernisme. CS merupakan sebuah komitmen interdisipliner (Morley, 2015). Dengan cara seperti itu, CS merupakan teori emansipasi (emancipations) plural. Meskipun demikian, Hall tidak sepenuhnya menerima secara pasif berbagai teori-teori tersebut, dan juga tidak berusaha membangun paradigma yang fixed bagi kajian-kajian budaya itu sendiri. CS juga disebut dengan teori transformasi kritis (Faruk, 2014; McQuillan, 2003; Critchely, 2003).

Kultur sendiri selalu mendapat definisi yang beragam. Kultur merupakan segala sesuatu yang tidak bisa dipisahkan dari kehidupan manusia. Sederhananya, apapun yang kita pakai atau kita makan, atau bagaimana cara sesorang bicara hingga berpikir adalah budaya. Jika seseorang berada di tempat berbeda, maka seseorang itu memasuki sebuah lingkup kultur yang baru pula. Kultur akan kelihatan (visible) apabila seseorang menjelajah lebih jauh antara dua kultur, dan atau seseorang itu menengok kembali kultur lain ketimbang kulturnya sendiri (Ryan, 2010). Kultur dengan demikian sebuah gambaran yang transformatif. Bagi Hall, kultur adalah sebuah proses yang harus diperjuangkan, bukan objek statis yang agung, yang me- lingkupi teori (Procter, 2004). Kultur tidak lagi dipahami sebagai dunia ide. Kultur adalah praktik, sebuah praktik yang signifikan, dan punya caranya sendiri dalam memproduksi makna. Perubahan substansi yang dikehendaki CS terkait dengan kultur adalah dari apa (what) menjadi bagaimana (how) (Hall, 2005).

Terkait kultur praktik tersebut, Hall menjelaskan salah satunya dalam persoalan bahasa dengan mengutip karya awal Lévi Strauss dan Barthes. Hall (2005) menggambarkan bahwa bahasa sebagaimana dipahami oleh mereka berdua adalah sebagai sebuah paradigma untuk studi kultural. Dengan anggapan serupa itu, bahasa dipahami secara lebih luas (bisa dikatakan juga tak terbatas). Bahasa yang merupakan medium produksi makna, pada umumnya dipahami terstrukturkan oleh sistem, yaitu sebuah ekspresi. Hall melihat bahwa pada gilirannya, bahasa bukan lagi sebuah sistem yang demikian. Bahasa adalah struktur atas variasi-variasi kemungkinan. Bahasa adalah susunan elemen-elemen terkait sebagai praktik, tindakan, atau perbuatan, bukan hanya ekspresi. Lévi Strauss menggunakan model demikian untuk mengubah bahasa-bahasa ke dalam bahasa masyarakat 'primitif' (misal: mitos-mitos). Sementara itu, Barthes menawarkan lebih banyak 'semiotik' yang tidak biasa, mempelajari sistem tanda dan susunan bahasa, kode dan praktik-praktik kehidupan sehari-hari dalam masyarakat kontemporer. Keduanya membawa istilah 'kultur' dari tingkatannya yang mulia atau tinggi, turun ke level antropologis, yaitu kehidupan sehari-hari. Artinya, bahasa pun demikian halnya sebagai praktik, bukan ekspresi.

Dengan mengubah substansi apa (what) yang terbatas sebagai ide menjadi bagai- 
mana (how) - proses tindakan (Regan, 2013), Hall menawarkan teori artikulasi. Artikulasi adalah untuk mengacaukan, untuk berkata seterusnya, untuk menjadi bersambung (Procter, 2004). Mengacaukan dapat diartikan menggoyahkan tatanan yang mapan; seterusnya dapat diartikan sebagai tidak ada titik yang selesai; bersambung dapat diartikan bahwa masih ada kelanjutannya dengan melihat dari berbagai sisi, atau kemungkinan-kemungkinan. Artikulasi dalam pengertian seharihari bahkan sangat sederhana yaitu upaya "bicara" terhadap situasi yang timpang atau tidak seimbang. Praktik-praktik artikulasi juga menjadi semacam "pergerakan" (Vincent, 2013). Atau, artikulasi juga dapat diartikan sebagai upaya membangun wacana terhadap suatu bentuk dominasi kultural (Hebdige, 2015: 33), dominasi sebuah rezim (Grossberg, 2014).

Contoh yang sering digunakan Hall adalah mengenai lorry (truk). Lorry bisa diartikan sebagai bagian depan truk (cab), juga bisa diartikan sebagai bagian belakang (trailer). Keduanya disebut lorry, meskipun terdiri atas bagian depan dan belakang. Keduanya merupakan elemen yang berbeda, tetapi terkait satu sama lain. Artinya, artikulasi adalah fragmen-fragmen dari sebuah kesatuan (Budiman, 2014). Atau, dengan kata lain bahwa kesatuan tidaklah satu, tetapi terdiri atas fragmen-fragmen. Artikulasi bisa dipahami sebagai teori juga sekaligus metode. Sebagai teori, artikulasi dapat dipahami sebagai pandangan untuk menggolongkan sebuah formasi sosial tanpa harus masuk dalam ranah reduksi dan esensi (Slack, 2005). Artinya, artikulasi tidak digunakan untuk membuat definisi-definisi secara konstruktif layaknya tujuan reduksi dan esensi. Artikulasi selalu merupakan praktik-praktik sosiologis.

Secara metodologis, artikulasi muncul dalam pengalaman (experience). Pengalaman merupakan kunci utama dalam CS (Pickering, 2008), dan demikian halnya dalam artikulasi. Adapun, cara kerja artikulasi terbagi dalam tiga level: epistemologi, politik, dan strategi (Slack, 2005). Level epistemologi adalah gambaran fragmenfragmen dari sebuah kesatuan, yaitu setiap bagian terkecil (subordinat) dari sebuah tatanan sosial adalah penting dan diakui keberadaannya dalam sebuah tatanan yang lebih besar lagi (ordinat). Level politis adalah cara mengedepankan tatanan kekuatan (dalam ranah sosial) yang bertanggung jawab atas munculnya relasi antara bagian kecil (subordinat/rakyat jelata/ proletar/kelas bawah) dan bagian utama (subordinat/penguasa/kelas atas). Pada level strategis, artikulasi merupakan sebuah mekanisme untuk menajamkan keikutsertaan di dalam formasi sosial khusus, serangkaian kejadian, ataupun konteks. Artinya, upaya-upaya strategis yang bagaimana, yang kemudian ditempuh oleh kelompok subordinat sehingga tetap menjadi bagian dari sebuah tatanan formasi sosial yang dominan, utama.

Dalam penelitian ini, yang dimaksud dengan pengalaman adalah gambaran kultural yang terdapat dalam sastra yaitu wujud pikiran-pikiran berbentuk ungkapan bahasa. Kendall (2001) mengajukan tiga tata cata (protocol) secara metodologis dalam CS, yaitu di antaranya: pertama, mendeskripskan segala kemungkinan yang muncul/kelihatan (epitemologis). Kedua, mendeskripsikan munculnya sebuah sistem dan cara berpikir (politis). Ketiga, mendeskripsikan fungsi atau kegunaan dari kemunculan itu (strategis). Sesuai dengan tema 
utama penelitian ini, maka artikulasi kelas bawah Jawa dalam puisi-puisi karya Wiji Thukul yang terkumpul dalam antologi Para Jenderal Marah-Marah diselidiki dalam tigal level yaitu epistemologis, politis, dan strategis.

Cultural Studies (CS) meyakini bahwa budaya atau kultur adalah sesuatu yang harus diperjuangkan. Kultur yang juga merupakan konsep dasar dari pembentukan kelas tidak bersifat definitif, tetapi lebih bersifat praktik. Artikulasi (articulation) ini pernah dan masih menjadi ruang perjuangan ras kulit hitam terhadap dominasi ras kulit putih di Eropa pada masanya. Kaitannya dengan penelitian ini, kelas bawah Jawa dalam representasi puisi Wiji Thukul juga memperjuangkan hal yang serupa, yaitu perjuangan kelas untuk mencapai keseimbangan, yang mana satu kelas tidak dominan terhadap kelas yang lain, atau satu kelas tidak didominasi atau tergantung kelas yang lain.

Cita-cita dari artikulasi adalah masyarakat dan atau budaya yang mandiri, bebas dikotomi, bebas dominasi, merdeka, tidak dalam tekanan budaya atau kelompok yang lain. Dengan asumsi demikian, penelitian ini penting dilakukan mengingat di era sekarang, problem multikulturalisme masih jauh dari cita-cita persamaan kelas (equality class). Walaupun, penelitian-penelitian yang sudah ada belum didominasi Selain itu, penelitian ini juga berupaya memberi pemahaman bahwa sastra tidak selalu hanya berurusan dengan teks tulis, tetapi ada cita-cita sosio-kultural yang bisa diperjuangkan. Oleh karena itu, masalah utama dalam penelitian ini adalah bagaimana artikulasi kelas bawah Jawa dalam puisi-puisi Wiji Thukul yang terkumpul dalam antologi Para Jenderal Marah-Marah?
Kajian-kajian atau penelitian sastra mengenai Cultural Studies belum banyak dilakukan di Indonesia, atau bahkan belum ada yang benar-benar serius. Meskipun demikian, permasalahan kelas sosial, baik yang terstruktur maupun yang acak sangat mungkin terjadi di negara yang multikultur seperti Indonesia. Kultur yang terbentuk di Indonesia sangat mungkin tidak bebas dari kepentingan-kepentingan. Artinya, sebuah kultur tidak terjadi secara alamiah, atau tidak bebas nilai. Sastra dengan porsinya, dapat pula sebagai perekaman atau potret kehidupan atas persoalan demikian.

\section{METODE}

Sesuai dengan anjuran Slack dan Kendall sebelumnya, CS dapat dioperasikan secara metodologis dengan tiga (3) level dan juga tiga (3) tata cara (protocol). Pertama, level epistemologis, yaitu mendeskripsikan fragmen-fragmen formasi sosial kelas bawah Jawa yang muncul dalam puisi. Fragmen adalah kelas bawah Jawa itu sendiri. Oleh karenanya, pada level ini pendeskripsian adalah berupa penguraian secara detail bagaimana posisi kelas bawah Jawa dalam tatanan besar formasi sosial Jawa pada umumnya.

Kedua, level politis, yaitu mendeskripsikan sistem, tatanan, atau cara berpikir sosial Jawa yang kemudian memunculkan kelas-kelas. Pendeskripsian pada level politis ini bertujuan untuk mengetahui bagaimana kelas bawah Jawa berpikir dan menciptakan sistem sekaligus juga bagaimana formasi sosial Jawa dalam tatanan yang lebih besar membangun sistem sosialnya. Ketiga, level strategis, yaitu mendeskripsikan tindakan kelas bawah Jawa dalam upayanya menjadi bagian yang setara (equal), sebagai fragmen dari sistem atau 
formasi sosial yang lebih besar yang melingkupinya $($ Jawa $=$ lokal, Indonesia $=$ nasional).

\section{HASIL DAN PEMBAHASAN}

Berdasarkan data yang diperoleh, bab ini akan menguraikan bagaimana puisipuisi Wiji Thukul yang terkumpul dalam antologi Para Jenderal Marah-Marah (2013) merepresentasikan secara artikulatif kelas bawah Jawa, atau lapis sosial masyarakat Jawa yang paling dasar. Pada umumnya, lapis paling bawah atau paling dasar sebuah struktur sosial masyarakat sering tidak mendapatkan perhatian serius mengenai bagaimana mereka bertahan hidup, bagaimana mereka menyesuaikan diri dengan segenap kebijakan-kebijakan elit, bagaimana mereka berasimilasi dengan normanorma yang berkembang terus-menerus dan sebagainya.

Puisi-puisi Wiji Thukul merepresentasikan kelas paling bawah Jawa, atau bisa juga dikatakan kelas rakyat (pedagang, tukang becak, penjual makanan dan minuman pinggir jalan, dan sebagainya) yang berupaya berasimilasi dengan perkembangan sosial-kultural di sekelilingnya, bernegosiasi dengan norma-norma yang bisa dipahami maupun yang tidak, berjuang untuk bertahan hidup dan sebagainya. Bab ini akan menguraikan bagaimana pola-pola demikian bisa dijelaskan dengan sudut pandang Cultural Studies yang mendorong semangat-semangat artikulatifnya sejak era Lingkaran Birmingham (Birmingham Circle).

Ada tiga (3) kategori besar dari data yang sudah dikumpulkan terkait dengan artikulasi kelas bawah Jawa dalam kumpulan puisi Wiji Thukul yaitu di antaranya: 1) negosiasi artikulatif perempuan kelas bawah Jawa, 2) negosiasi artikulatif laki-laki kelas bawah Jawa, 3) negosiasi artikulatif struktural kelas bawah Jawa. Pengategorian tersebut tidak bersifat kaku dan terkotak-kotak. Pada gilirannya, dalam subpermasalahan tertentu yang diuraikan, masing-masing bisa saling terkait.

\section{Negosiasi Artikulatif Perempuan Kelas Bawah Jawa}

Dunia angan Wiji Thukul yang mewujud dalam puisi-puisinya berbeda dengan dunia angan Jawa dalam tataran "luhur" seperti yang dituliskan serat atau babad. Misalnya nilai kesempurnaan hidup (ngudi kasampurnan) dan filsafat asal (sangkan paraning dumadi) yang dituliskan secara rinci oleh Wibawa (2013: 332). Thukul justru tidak tertarik membangun angan "luhur" tersebut, tetapi justru tertarik mengupayakan praktik-praktik kultural yang konkret mengenai dunia ide.

Kata "negoisasi" dalam hal ini dimaknai sebagai "daya tawar" agar segala bentuk konstruksi (ide-ide) tidak berlangsung atau terjadi secara absolut. Oleh karena itu, bisa dikatakan pula bahwa negosiasi (yang artikulatif) ini beroposisi dengan absolutisme (segala hal yang mutlak, tidak bisa ditawar lagi). Perempuan kelas bawah, atau perempuan yang posisi kulturalnya berada di tingkat dasar struktur masyarakat, dalam puisi-puisi Wiji Thukul digambarkan secara artikulatif mempunyai daya negosiasi terhadap apa yang mereka hadapi. Hal demikian dapat dilihat pada kutipan puisi berikut di bawah ini.

WARUNG KOPI YU YEN
"Mangga mampir mas!"
ngunjuk kopi napa jahe
sekul bothok napa oseng-oseng

WARUNG KOPI YU YEN

sekul bothok napa oseng-oseng 


\author{
nedhine \\ yen kebelet nguyuh \\ mang nguyuh ten mburi niku \\ yen kadhemen \\ mang kemulan \\ niki wonten kemul anyar \\ kemule saged ngentut \\ jenenge narti!
}

(Thukul, 2013: 23)

WARUNG KOPI YU YEN

"Mari mampir mas!"

minum kopi atau jahe

nasi bothok atau tumis

makannya

kalau kebelet kencing

kencinglah di belakang itu

kalau kedinginan

silakan berselimut

ini ada selimut baru

selimut bisa kentut

namanya narti!

(Thukul, 2013: 23)

Yu (Mbak ayu [Jawa] = perempuan yang tingkatnya lebih dewasa dilihat dalam tingkatan umur) Yen dalam puisi tersebut, posisi kulturalnya lebih "tinggi" daripada Narti. Alasannya, Yu Yen seperti terlihat dalam judul adalah pemilik warung kopi (Warung Kopi Yu Yen). Narti sendiri digambarkan "setara" dengan segelas kopi. Ia (Narti) ditawarkan kepada pembeli yang posisi kulturalnya lebih tinggi baik dari Yu Yen, maupun Narti.

Posisi kultural tersebut, apabila diurutkan dari yang paling tinggi hingga yang paling rendah adalah: pembeli, penjual (Yu Yen), dan barang dagangan (kopi, dan Narti). Relasi antara ketiganya terjadi tidak dengan kesetaraan. Posisi pembeli berada di puncak kultural, disusul kemu- dian dengan penjual yang menempati posisi kultural di tengah, dan di posisi paling bawah adalah barang dagangan yang selain kopi juga terdapat nama Narti (perempuan Jawa). Ketika relasi dalam bentuk tingkatan demikian terjadi dalam satu kelas yang sama, atau lapis kehidupan yang sama yaitu, kelas bawah Jawa. Asumsinya adalah bahwa dalam kelas bawah Jawa, secara kultural masih terdapat tingkatantingkatan (kelas) sesuai posisinya.

Posisi, tingkatan, dan atau kelas tersebut tidak terjadi secara alami (natural $=$ terjadi begitu saja). Namun, hal demikian terjadi karena dorongan berbagai kepentingan. Pembeli punya kepentingan mendapatkan "kepuasan" dan "kenikmatan" baik dalam hal rasa, pelayanan, dan hal lainnya. Oleh karena pembeli adalah sasaran dari penjual dan barang dagangannya maka penjual memosisikan pembeli memiliki posisi kultural lebih tinggi dari dirinya.

Posisi yang didapatkan Narti baik dalam tekanan kultural penjual (Yu Yen), maupun dalam tekanan kultural pembeli terbukti tidak terjadi secara alami. Narti mendapat tekanan kultural atas kepentingan-kepentingan, baik kepentingan mendapatkan uang, kepuasan, atau kenikmatan. Kepentingan Narti sendiri adalah bertahan hidup, walaupun di dalam lingkaran atau lingkup kehidupan kultural yang sama.

Letak negosiasi artikulatifnya tidak terdapat pada bagaimana Narti direpresentasikan dalam puisi. Namun, letak yang dimaksud terlihat dari keseluruhan puisi itu sendiri. Alasannya, tema yang diangkat secara kultural mewakili bagaimana perempuan Jawa hidup dalam kelas sosialkultural yang sama sekali tidak mudah. Negosiasi yang ditawarkan dalam hal ini 
tidak secara gamblang (eksplisit), melainkan secara samar (implisit).

Narti tidak digambarkan melakukan perlawanan atau negosiasi terhadap posisi kultural yang diposisikan kepadanya dalam puisi itu. Sebagai perempuan Jawa yang dikonotasikan dengan barang dagangan (setara dengan segelas kopi), Narti tidak digambarkan melakukan pembelaan. Artinya, ia (Narti) bukan sebagai subjek, tetapi sebagai objek. Sebagai manusia, Narti adalah barang dagangan karena desakandesakan kepentingan kultural. Tema inilah yang sifatnya artikulatif. Pelaku-pelaku (Narti) yang diinterpretasikan secara eksplisit tidak langsung artikulatif, tetapi tema besar kelas Jawa yang digambarkan dalam puisi tersebut sifatnya artikulatif. Pilihan untuk menggambarkan bagaimana kelas bawah terpisah kedudukan kulturalnya atas dorongan kepentingan (materi) adalah upaya artikulatif yang implisit. Namun, selain implisit, negosiasi kultural serupa itu digambarkan juga secara eksplisit khususnya berkaitan dengan perempuan kelas bawah Jawa. Hal tersebut dapat dilihat pada kutipan berikut ini.

ASIH PUNK ROCK
"Aja takon ngendi omahku mas!"
Bapakku pegatan kawin maneh karo
prawan
Adhiku papet sekolahe berantakan
saben ndina usrek aku ora kerasan
"Aja takon pira umurku mas!"
Telung taon kepungkur aku kelas
loro smp
Prawanku ilang dimaling lanangan
"Aja takon iki jam pira mas!
Wengi iki aku kelonana
Ora bakal ana wong nggoleki
... (Thukul, 2013: 23)

\section{ASIH PUNK ROCK}

"Jangan tanya rumahku mana mas!" Bapakku cerai menikah lagi dengan perawan

Adikku berhenti sekolah berantakan tiap hari gelisah aku tidak kerasan "Jangan tanya berapa umurku mas!" Tiga tahun lalu aku kelas dua smp Perawanku hilang dimaling lelaki “jangan tanya ini jam berapa mas! Malam ini tiduri aku

Tidak ada yang bakal mencari ... (Thukul, 2013: 23)

Asih atau "aku" lirik dalam puisi "Asih Punk Rock" tersebut direpresentasikan sebagai perempuan Jawa kelas bawah yang artikulatif secara eksplisit. Asih adalah perempuan kelas bawah Jawa yang jika diposisikan dalam struktur kultural sebelumnya adalah "penjual" sekaligus "barang dagangan". Artinya, ia merepresentasikan dirinya dalam dua lapis sosial secara bersamaan.

Asih memosisikan diri sebagai "penjual" dan "barang dagangan" sekaligus dengan asumsi bahwa secara kultural ia didorong oleh kepentingan-kepentingan yang tidak alamiah. Kepentingan-kepentingan tersebut kemudian membuat posisi kultural Asih menjadi ambigu. Ia tidak sebagai kelas bawah yang berada dalam posisi tengah, tetapi juga berada dalam posisi yang bawah. Ia berada dalam kultur sosial yang tidak jelas. Kultur tidak alami demikian itulah yang melahirkan sikap artikulatif bahwa Asih tidak dalam posisi kultural yang wajar lazimnya anak sekolah misalnya karena sudah tidak perawan. Asih juga dalam kondisi sosial yang tidak alami sebagaimana seorang anak pada umumnya yang akan 
dicari orang tuanya ketika menginap di rumah lain. Asih justru menawarkan dirinya sebagai "teman tidur" oleh pembeli yang mampu membayar dengan sejumlah uang. Asih melawan mitos kultural yang lazim, normatif (sesuai norma) dengan kultur yang tidak lazim, tidak sesuai norma. Asih membuat angan artikulatifnya menjadi visible dengan praktik-praktik yang dilakukannya (Ryan, 2010).

Asih tidak sekedar menerima kondisi tersebut secara alamiah, tetapi ia bisa disebut melakukan negosiasi, atau perlawanan terhadap mitos alami perempuan Jawa pada umumnya. Dorongan, desakan, dan benturan kepentingan menjadikan Asih sebagai representasi perempuan kelas bawah Jawa yang artikulatif. Konsep artikulasi ini berbeda dengan konsep "kemandirian" sebagaimana digambarkan Harjito (2014: 322) dalam kehidupan Nyai Jawa. Artikulasi tidak menerima begitu saja apa yang terjadi pada dirinya, tetapi "bergerak" untuk kondisi kultural yang lain, yang belum tentu juga merupakan kondisi kultural yang lebih baik. Selain puisi "Asih Punk Rock", perempuan Jawa digambarkan secara ideal dalam puisi "Asmaradana" seperti terlihat pada kutipan berikut di bawah ini.

ASMARADANA
mabura
mabura menyang ngendi
aku ora nggondheli
mabura
mabura tekan ngendhi
aku tetep nututi

tresnaku merdhika cah ayu!

(Thukul, 2013: 25)

\author{
ASMARADANA \\ terbanglah \\ terbanglah ke mana \\ aku tidak akan menghalangi \\ terbang \\ terbang sampai di mana pun \\ aku tetap akan mengikuti \\ cintaku merdeka hai cantik! \\ (Thukul, 2013: 25)
}

Ideal yang dimaksud juga atas dasar kepentingan yaitu kepentingan untuk "bebas" atau "merdeka". Kata mabur 'terbang' menggambarkan sebuah "pergerakan" dari kondisi semula ke kondisi yang berbeda. Pada baris: / mabura menyang ngendi (terbanglah ke mana) / aku ora nggondheli (aku tidak akan menghalangi) direpresentasikan bahwa kondisi yang ideal bagi perempuan Jawa kelas bawah adalah kondisi "bebas" (mabur = terbang), tidak ada halangan, tidak ada tekanan. Hal ini yang disebut Stuart Hall sebagai fragmen-fragmen (Budiman, 2014). Perempuan adalah fragmen dari konstruksi besar kultural Jawa. Apabila perempuan Jawa kelas bawah adalah perempuan yang tertekan, tidak bebas, maka representasi perempuan dalam puisi "Asmaradana" adalah kebalikannya.

Laki-laki, atau "aku" lirik dalam puisi tersebut memberikan keleluasaan tanpa tekanan, dan dengan begitu ia masih bersikap untuk tetap mendukung kebebasan perempuan kelas bawah Jawa untuk menentukan sendiri posisi kulturalnya tanpa tekanan kepentingan apa pun atau siapa pun. Hal itu terlihat dalam baris: / mabura tekan ngendhi (terbanglah sampai mana) / aku tetep nututi (aku tetap akan mengikuti/ mendukung). Baris puisi ini justru menggambarkan sosok perempuan yang berada 
di depan, bebas menentukan sikap, sedangkan laki-laki di belakang: mengikuti, dan mendukung. Konsep ini yang dalam puisi tersebut disebut sebagai "tresna" atau cinta. Oleh karena itu, tresna atau cinta dalam konsep puisi tersebut adalah gerakan kultural untuk saling membebaskan, atau pembebasan perempuan menentukan sendiri posisi kulturalnya. Tresna dalam konsep Wiji Thukul oleh karenanya dekat dengan sebuah "pergerakan". Tresna ini juga menjadi pergerakan dalam upaya membangun wacana terhadap bentukbentuk dominasi kultural ataupun mitos (Vincent, 2013); (Hebdige, 2015); (Grossberg, 2014).

Mitos perempuan Jawa pada umumnya adalah pasrah, statis, sebagai objek, dan dalam kontrol penuh laki-laki. Sementara itu, seperti halnya dengan pandangan Cultural Studies, perempuan Jawa dalam puisi tersebut didorong ke dalam posisi kultural yang baru, atau mitos yang baru bahwa perempuan Jawa adalah perempuan yang: merdeka, dinamis, sebagai subjek, dan dalam dukungan laki-laki. Hal demikian menjadi bukti bahwa posisi kultural perempuan kelas bawah Jawa dalam puisi tersebut punya "daya tawar" atau "negosiasi" yang sifatnya artikulatif.

\section{Negosiasi Artikulatif Laki-Laki Kelas Bawah Jawa}

Selain perempuan, laki-laki juga direpresentasikan secara artikulatif dalam puisipuisi Wiji Thukul. Persoalan kultural yang dihadapi laki-laki tidak jauh berbeda dengan perempuan. Laki-laki dalam beberapa puisi tidak digambarkan juga sebagai manusia yang statis, melainkan sebagai lagilagi dalam posisi kulturalnya yang selalu bergerak dinamis. Hal demikian dapat di- lihat pada kutipan puisi berikut ini.

AKU DUDU SATRYA
yen kiwa tengen kebak wong
dipulasara
aku ora arep mungguh gunung tapabrata
yen kiwo tengen pating njlerit
aku ora arep nyepi ing ringin-ringin
wingit
aku dudu satrya
aku dudu pangeran sing arep
munggah nata
aku rakyat biasa
menungsa cilik sing nduwe tangga

(Thukul, 2013: 25)

\author{
AKU BUKAN SATRIA \\ kalau kiri kanan penuh orang \\ disiksa \\ aku tidak mau naik gunung bertapa \\ jika kiri kanan menjerit-njerit \\ aku tidak akan menyendiri di ringin-ringin \\ angker \\ aku bukan satria \\ aku bukan pangeran yang mau \\ naik nata \\ aku rakyat biasa \\ manusia kecil yang punya tetangga \\ (Thukul, 2013: 25)
}

Kata "satrya" atau "satria" merepresentasikan lapis sosial atas atau kalangan elit, atau pejabat, dan sebagainya. Puisi tersebut menggunakan judul "Aku Dudu Satrya" atau "Aku Bukan Satria" yang menggambarkan bahwa aku lirik bukanlah golongan atau lapisan kelas atas atau elit.

Puisi tersebut merepresentasikan oposisioposisi kultural yang melekat pada lakilaki (Jawa) pada umumnya. Oposisi tersebut misalnya terlihat pada baris: / aku 
dudu satrya (aku bukan satria)/aku dudu pangeran sing arep (aku bukan pangeran yang mau)/munggah nata (naik nata [tahta]). Baris tersebut mengatakan bahwa satria, pangeran, atau elit bukanlah identitas kultural, atau posisi kultural yang diinginkan. Posisi yang diinginkan atau yang diangankan justru secara nyata adalah rakyat biasa seperti dalam baris: / aku rakyat biasa (aku rakyat biasa)/menungsa cilik sing nduwe tangga (manusia kecil yang punya tetangga)/.

Baris-baris puisi tersebut, selain sifatnya oposisional juga secara kultural adalah sebuah bentuk semangat yang dinamis (bukan statis). Apa yang dimaksud dinamis adalah "daya tawar" atau "negosiasi" dari satu bentuk konseptual sebuah kultur ke dalam konsep kultural yang lain. Satria dan rakyat biasa adalah lapis sosial yang saling beroposisi. Satria atau pangeran mewakili konsep "ideal" manusia, yaitu: pertapa, punya tahta, agung, sedangkan rakyat mewakili konsep "sosial" yaitu: punya rasa sakit, punya saudara/tetangga yang setara kedudukannya, dan jelata. Konsep ideal lebih susah dijangkau secara kultural karena selain digambarkan mendekati wilayah yang sakral, agung, juga mendekati kondisi kultural yang absolut. Konsep sosial lebih mudah dijangkau karena merupakan kondisi yang sangat mendasar dari manusia itu sendiri yaitu: mempunyai rasa sakit, solider dengan kondisi tetangga atau manusia yang lain. Oleh karena itu, sejalan dengan Cultural Studies sebagaimana diserukan oleh Stuart Hall bahwa puisi "Aku Dudu Satrya" menawarkan sebuah konsep kultural yang mengacaukan mitos ideal pada umumnya menjadi konsep sosial yang lebih nyata. Ideal adalah what, dan diubah perannya menjadi how. Ideal menjadi praktik sosial (Regan, 2013).
Laki-laki kelas bawah Jawa digiring ke arah konsep kultur yang bersifat sosial ketimbang ideal: tidak berusaha membangun angan-angan tinggi (naik gunung bertapa), tetapi jauh lebih membumi, yang apabila ada sesama manusia yang kesakitan atau butuh bantuan lebih terjangkau untuk saling membantu. Artinya, konsep ideal adalah mitos yang kemudian dikacaukan untuk membangun mitos baru yaitu konsep sosial yang lebih dinamis. Konsep sosial demikian digambarkan secara kritis dalam puisi lainnya yang berjudul "Jimat Sekti" seperti dapat dilihat pada kutipan berikut di bawah ini.

JIMAT SEKTI
wong lanang kudu menang
wong wedhok kudu ngalah
wong lanang ngekep jagad
wong wedok ra kena mbantah
wong lanang kena saba sakdalandalan
wong wedok wis mesthine ning
ngumah
wong lanang bedhigasan ora nggenah
wong wedok ora wani obah
wong lanang kuwi pancen ngglathak
licik lucu lan mamak
karepe wong wedok mung dikon
mlumah ngglethak
yen gregah-gregah arep tangi
gage-gage diagar-agari jimat sakti
sing jenenge norma adat tradisi
(Thukul, 2013: 25)
JIMAT SAKTI
laki-laki harus menang
perempuan harus mengalah
laki-laki memeluk jagad
perempuan tidak boleh membantah
laki-laki boleh berkeliaran sepanjang jalan
perempuan sudah sepantasnya di

JIMAT SEKTI

wong lanang kudu menang

wong wedhok kudu ngalah

wong lanang ngekep jagad

wong wedok ra kena mbantah

wong lanang kena saba sakdalandalan

thine ning

ngumah

wong lanang bedhigasan ora nggenah

ngglathak

licik lucu lan mamak

yen gregah-gregah arep tangi

gage-gage diagar-agari jimat sakti

sing jenenge norma adat tradisi 
rumah

laki-laki bebas tidak jelas

perampuan tidak berani bergerak

laki-laki itu memang rakus

licik lucu dan mamak

maunya perempuan hanya disuruh

tiduran telentang

kalau menggeliat mau bangun

segera ditakut-takuti jimat sakti

yang dinamai norma adat tradisi

(Thukul, 2013: 25)

Posisi laki-laki dalam puisi tersebut digambarkan oposisional dengan posisi perempuan dalam konteks kelas bawah Jawa. Laki-laki adalah yang menang, sedangkan perempuan adalah yang kalah (mengalah). Laki-laki mendekati absolut, perempuan mengkritik pun tidak bisa. Laki-laki di luar rumah (eksploratif), perempuan di dalam rumah (domestik). Lakilaki boleh ngawur dan tidak jelas, perempuan tidak diperkenankan melakukan apaapa. Laki-laki boleh mengumbar birahi, perempuan (hanya) boleh menerima birahi itu.

Oposisi-oposisi tersebut tidak terjadi secara alamiah, atau begitu saja terjadi, melainkan atas kepentingan-kepentingan. Dorongan besar yang menjadikan kepentingan-kepentingan tersebut muncul adalah norma yang turun-temurun dalam kalangan kelas bawah Jawa. Norma yang dimaksud disampaikan dalam puisi tersebut dengan simbolisasi "Jimat" yang "Sakti". Jimat adalah wujud atau konsep kultural yang "magis", mempunyai kekuatan, dan bisa dibilang antikritik, atau antilogika. Jimat adalah entitas yang kuat tanpa perlu penjelasan apa-apa. Jimat menjadi kuat secara alami, atau terjadi begitu saja, dan orang tidak perlu, atau dibuat tidak perlu menanyakan alasan secara logisnya bagaimana hal itu bisa terjadi (kebal: antikritik). Norma yang sakti, yang dapat diartikan juga kebal: antikritik tentu mengakibatkan mitos yang sulit dijangkau. Lakilaki dengan demikian secara gamblang dan satir digambarkan selalu menang terhadap perempuan.

Puisi tersebut oleh karenanya secara kritis ingin menunjukkan bahwa ada norma yang mendekati absolut yang berkembang dalam tradisi Jawa pada umumnya. Norma tersebut mendorong lahirnya klasifikasi dan atau stratifikasi sosial yang sifatnya oposisional terhadap posisi kultural laki-laki dengan perempuan. Lakilaki sebagai sebuah kekuatan secara vulgar ditempatkan layaknya "penindas" yang menghendaki segala kepentingan bersumber atau berlandaskan untuk memenuhi kepentingannya itu. Gambaran demikianlah yang baik secara eksplisit maupun implisit disajikan dalam puisi tersebut sebagai mitos. Upaya kritis tersebut menegaskan kembali bahwa laki-laki penindas sebagai mitos dikacaukan agar bisa "ditawar" atau "dinegosiasi" sehingga tidak ada lagi norma yang absolut dan antikritik, dan tentu saja penindasan. Hal itulah yang menjadi tujuan Cultural Studies yaitu selalu berusaha mengacaukan tatanan ideal yang mapan untuk memberikan ruang alternatif yang terus-menerus terbuka (Hall, 2005); (Procter, 2004).

\section{Negosiasi Artikulatif Struktural Kelas Bawah Jawa}

\author{
RECO NGGLADAG \\ reco nggladag \\ coba takona \\ bocah-bocah kuwi anake sapa
}




\author{
apa kupingmu ora risi \\ krungu cekikikane bocah-bocah kuwi \\ coba takonana omahe ngendi \\ iki wis bengi \\ coba tamatna sopir-sopir becak kae \\ turu angler ora sarungan \\ apa sing dienteni? rejeki? \\ reco nggladag \\ tulung \\ jawilna sutinah \\ sing rambute dawa diklebang loro \\ kuwi \\ mengko esuk arep turu ngendhi?
}

(Thukul, 2013: 24)

ARCA NGGLADAG
arca nggladag
coba tanyakan
anak-anak itu anaknya siapa
apa kupingmu tidak risi
mendengar tawa anak-anak itu
coba tanyakan rumahnya mana
ini sudah malam
coba lihat baik-baik sopir-sopir becak itu
tidur nyenyak tidak bersarung
apa yang ditunggu? Rezeki?
arca nggladag
tolong
jawilkan sutinah
yang rambutnya panjang dikelabang dua
itu
pagi nanti hendak tidur di mana?
(Thukul, 2013: 24)

Struktur yang dimaksud adalah kontruksi atau sistem sosio-kultur kelas bawah Jawa. Oleh karena struktur ataupun sistem, maka hal demikian berkaitan dengan bagaimana sebuah masyarakat dikonstruksikan baik dalam berupa kebijakan-kebijakan yang sifatnya datang dari pemerintah, atau yang datang dari pihak penguasa se- buah institusi, dan atau kebijakan lainnya. Hal serupa terjadi juga dalam puisi berjudul "Reco Nggladag".

Ada sekian pertanyaan artikulatif yang muncul dalam puisi tersebut. Misalnya pertanyaan mengenai identitas anak-anak yang tidak jelas; keberadaan tukang becak yang kelihatan tidak meyakinkan; nama Sutinah yang menandakan identitas perempuan dan juga dalam posisi tidak jelas. Pertanyaan-pertanyaan tersebut menandakan bahwa kultur demikian tidaklah alami. Apakah yang dimaksud sebagai anak? Jawabannya tentu ia punya orang tua, punya rumah, dan pada saatnya pulang pastilah bergegas pulang. Apakah yang dimaksud dengan tukang becak? Jawaban yang jelas tentu adalah penjual jasa. Meskipun antara jasa dan rezeki tidak bisa diterangkan dengan gamblang relasinya seperti apa. Apa yang dimaksud dengan perempuan Sutinah? Ciri yang disematkan tentu adalah perempuan polos yang mengalami kebingungan-kebingungan menentukan tujuan.

Pertanyaan-pertanyaan itu ditujukan kepada sebuah reco (arca) yang merupakan sebuah patung. Atau, hal itu bisa juga dikatakan sebagai sebongkah batu. Artinya, pertanyaan itu sendiri adalah pertanyaan artikulatif yang tertuju pada struktur sosial besar yang melingkupi orang-orang kelas bawah tersebut. Arca tentu tidak akan menjawab, di samping tidak memiliki jawabannya. Namun, puisi itu sendirilah yang artikulatif paling tidak untuk menanyakan secara kritis, dan tidak membiarkan keadaan seakan terjadi secara alami tanpa desakan atas dorongan kepentingan-kepentingan. Oleh karena itu, artikulasi itu ditujukan kepada kebijakan-kebijakan, aturanaturan, ataupun undang-undang yang 
mengatur kesejahteraan rakyat pada umumnya. Hal serupa dapat dilihat dalam kutipan puisi lain berikut ini.

\section{GEGURITAN IKI MUNG PENGIN KANDHA \\ geguritan iki mung pengin kandha ing njaba ana wong sambat ngaluara sajake bubar dipulasara swarane ora cetha gremeng-gremeng ing petengan cangkeme pecah awak sekojur abang biru apa kowe ora krungu? coba lirihna omonganmu mbok menawa kowe ngerti apa karepe geguritan iki mung aweh kabar ing njaba bathang bosok pirangpirang apa irungmu ora mambu thok! thok! thok! sing teka aku kana lawangmu ngakna} (Thukul, 2013: 24)

\section{GEGURITAN INI CUMA MAU} BILANG

geguritan ini cuma mau mengatakan di luar ada orang merintih kesakitan sepertinya habis disiksa suaranya tidak jelas lirih-lirih dalam gelap mulutnya pecah seluruh badan merah biru apa kamu tidak mendengar? coba pelankan bicaramu apa maunya geguritan ini hanya ingin berkabar di luar banyak bangkai busuk apa hidungmu tidak menciumnya thok! thok! thok! yang datang aku sana bukakan pintumu

(Thukul, 2013: 25)

Puisi dengan judul "Geguritan Iki Mung Pengin Kandha" adalah representasi tuntutan: rasa aman, rasa dilindungi, perlakuan adil, dari sebuah sistem besar yang menaungi sebuah negara. Hal demikian dapat dilihat pada penggalan kutipan berikut ini.

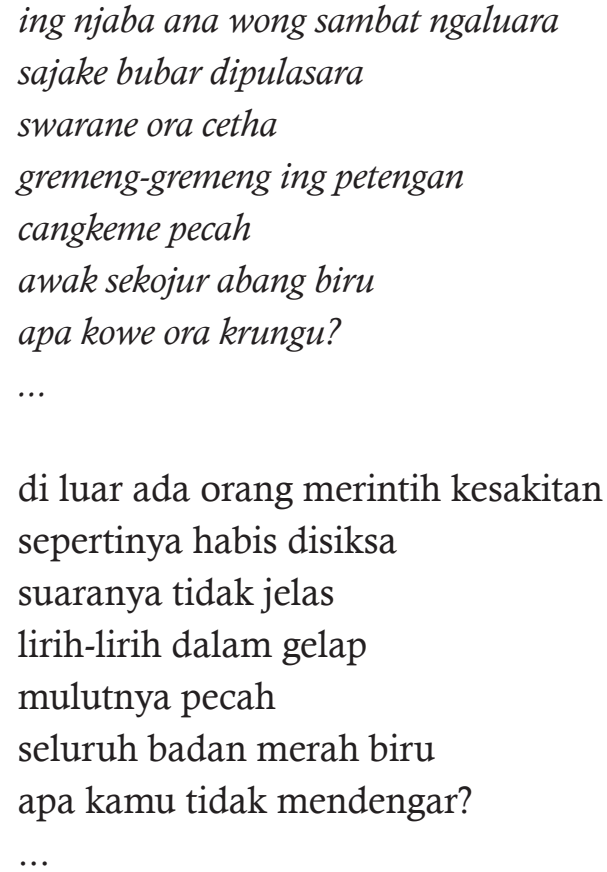

Penggalan puisi tersebut menggambarkan seseorang yang mendapat perlakuan tidak adil yaitu: dipulasara atau disiksa. Peraturan negara mana pun tidaklah mengizinkan siapa pun menyiksa, atau mengizinkan siapa pun disiksa. Ada hukum, dan ada proses hukum, apa pun dugaan kesalahan dari orang yang disiksa itu. Oleh karena itu, puisi ini artikulatif dalam kaitannya dengan melawan mitos besar kekuasaan yang absolut. Apa yang dimaksud dengan kekuasaan absolut secara struktural adalah bahwa sebuah kekuasaan seolah 
diatur sedemikian rupa sehingga lebih berpihak kepada kekuatan (politik) di belakang kekuasaan itu sendiri ketimbang berpihak kepada rakyat kecil yang rentan mendapatkan perlakuan tidak adil atas dugaan kesalahan yang dilakukannya. Berikut ini adalah kutipan puisi selanjutnya.

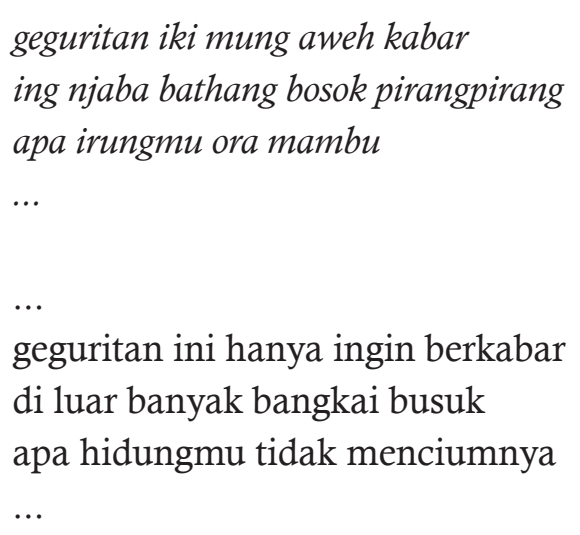

Penggalan puisi berikutnya ini menunjukkan bahwa tidak hanya penyiksaan yang menimbulkan efek kesakitan, tetapi juga ada tindak lanjut yang lebih jauh lagi yaitu terjadinya kematian (banyak bangkai busuk). Artikulasi dari puisi tersebut menyasar pada hak-hak untuk hidup bagi tiap warga negara yang dilindungi undang-undang, yang pada gilirannya tidak diperhatikan. Apabila menyiksa saja sudah merupakan tindakan yang melanggar hukum, tentu membunuh, atau merampas hak hidup manusia adalah pelanggaran hukum yang berat. Hukum yang mengatur hal demikian seolah mitos besar penguasa yang berpihak pada kekuatan penguasa itu sendiri ketimbang rakyat kelas bawah. Persoalan yang hampir sama dapat dilihat pada puisi "7 Agustus 1987" berikut ini.

\section{AGUSTUS 1987}

isih turu aku digugah adhiku

dheweke mbengak: aku klebu

sipenmaru!

maca koran sing didudahake

"Endi?"

adhiku nggregeli

drijine nduding jenenge

"Iki Iho......."

adhiku bungahe ora karuan

(sida dadi mahasiswa!)

simbok melu bingung

pamer tangga kiwo tengen

"Mbayar pira?"

"Satus telung puluh lima ewu!"

simbok ndomblang

nyawang isen-isen omahe.

(Thukul, 2013: 24)

\section{AGUSTUS 1987}

masih tidur adik membangunkanku

dia berteriak: aku masuk

sipenmaru!

baca koran yang dibuka

"Mana?"

adikku gemetar

jarinya menunjuk namanya

"Ini lho ..."

adikku senang bukan kepalang

(betul-betul jadi mahasiswa)

simbok ikut bingung

pamer tetangga kiri kanan

"Mbayar berapa?"

"Seratus tiga puluh lima ribu!"

simbok melongo

melihat isi rumah

(Thukul, 2013: 24)

Puisi "7 Agustus 1987" adalah representasi sistem pendidikan yang tidak berpihak pada kelas bawah atau rakyat jelata. 
Hal demikian, seperti pada pembahasanpembahasan sebelumnya adalah persoalan yang tidak alami, atau terjadi begitu saja. Secara struktural, pendidikan di sebuah negara diatur oleh kekuasaan suatu negara sehingga rakyat adalah sekelompok orang yang akan melaksanakan sistem tersebut. Apabila sistem tersebut tidak diatur sesuai dengan kemampuan atau daya capai rakyatnya, maka akan muncul ketidakmampuan, ketidakberdayaan, dan ketidakadilan.

Ada seorang anak yang diterima kuliah, tetapi hal demikian tidak kemudian ditanggapi dengan kegembiraan karena untuk dapat kuliah tentu membutuhkan biaya tidak sedikit. Pada baris:/"Mbayar pira?" (membayar berapa/berapa biayanya?)/ menandakan bahwa halangan utama dalam konteks itu adalah biaya. Artinya, sebagai rakyat jelata, keluarga tersebut (aku, adik, dan simbok) tidak merupakan bagian utuh dari sebuah struktur yang sistemik, yang menaungi kehidupannya. Hal itu juga bisa diartikan bahwa pendidikan secara umum belum berpihak pada kepentingan rakyat jelata. Oleh karena itu, kondisi kultural demikian tidak terjadi secara alami, tetapi ada aturan-aturan politis yang tidak bebas nilai atau mempunyai kepentingan-kepentingan tertentu. Puisi tersebut sebagai "daya tawar" atau "negosiasi" artikulatif yang kritis terhadap kenyataan struktural kelas bawah Jawa yang tidak berada dalam posisi seimbang. Mereka (kelas bawah Jawa) masih mengalami ketidakmampuan, ketidakberdayaan yang terstruktur.

\section{SIMPULAN}

Persoalan-persoalan artikulatif kelas bawah Jawa yang muncul dalam puisipuisi Para Jenderal Marah-Marah karya
Wiji Thukul disebabkan atau dilandasi karena beberapa faktor penting, yaitu: pertama, perempuan masih belum mendapatkan posisi "negosiasi" secara kultural sehingga perlakuan terhadapnya pun belum berimbang. Kedua, laki-laki masih menempati posisi yang tinggi, adiluhung, mendekati absolut, dan belum terdapat nalar kritis untuk mempertanyakan atau menggugat hal tersebut. Ketiga, sistem secara struktural, terkait kebijakan-kebijakan, aturan-aturan, atau norma-norma diatur dengan tidak berpihak kepada kelas bawah/rakyat jelata sehingga masih banyak ketidakberdayaan, ketidakmampuan, dan ketidakadilan.

Kemudian, artikulasi kelas bawah Jawa sendiri terjadi dalam beberapa kasus, yaitu: pertama, negosiasi perempuan kelas bawah Jawa dengan tujuan mengacaukan posisi kultural laki-laki yang mendekati absolutisme. Hal ini berkaitan dengan "daya tawar" perempuan untuk mendapatkan posisi kultural yang seimbang. Kedua, pengungkapan sisi kultural laki-laki dari sisi yang lain, yang menunjukkan nilai-nilai yang bertolak belakang dengan nilai-nilai adiluhung yang melekat daripadanya dengan tujuan menimbulkan chaos, melawan mitos, dan membangun mitos baru bahwa lakilaki tidaklah sepenuhnya adiluhung dan atau bahkan mendekati absolutisme. Lakilaki dalam hal ini digambarkan sebagai manusia yang lebih dekat dengan dunia luar rumah termasuk juga mendekati halhal yang bertentangan dengan norma seperti misalnya maksiat. Kondisi ini memberi peluang perempuan untuk mendapatkan posisi kultural yang seimbang sementara laki-laki mengalami kekacauan (utter) atau chaos dalam posisi kulturalnya.

Ketiga, sistem yang secara struktural 
diatur sedemikian rupa oleh narasi besar atau negara yang belum berpihak kepada kepentingan rakyat kelas bawah. Sistem ini secara artikulatif diungkap kekurangan atau ketidakberpihakannya kepada rakyat dengan masih adanya indikasi ketidakberdayaan, ketidakmampuan, dan ketidakadilan dalam berbagai aspek kehidupan kelas bawah, misalnya persoalan hak asasi manusia dan sistem pendidikan. Oleh karena itu, bisa dikatakan pula bahwa ketidakberdayaan, ketidakmampuan, dan ketidakadilan terkait hak asasi manusia, sistem pendidikan itu terjadi secara terstruktur, disadari, dan lebih berpihak pada kepentingan pemilik kekuasaan saja. Pengungkapan secara artikulatif kekurangan atau ketidakberpihakan kepada kelas bawah itu bertujuan untuk mengacaukan dan menunjukkan secara nyata implikasi negatifnya terhadap rakyat kelas bawah itu sendiri.

\section{UCAPAN TERIMA KASIH}

Penelitian ini adalah salah satu penelitian yang mendapat dana Hibah DIPA Kopertis wilayah V Daerah Istimewa Yogyakarta pada tahun 2016. Oleh karena itu, ucapan terima kasih saya sampaikan kepada Kemenristek DIKTI melalui Kopertis Wilayah $\mathrm{V}$ yang bersedia memberikan dukungan dana sehingga penelitian ini bisa terlaksana. Selain itu, ucapan terima kasih saya ucapkan kepada seluruh kolega di PBSI UST yang selalu membantu wacana dialektika terutama dalam hal analisis.

\section{DAFTAR PUSTAKA}

Ang, Ien. (2013). "Cultural studies matters (does it ?): engaging inter/disciplinarity" in Inter-Asia Cultural Studies, Vol. 14, No. 3, page 433.
Belsey, Catherine. (2003). "From Cultural Studies to Cultural Criticism?" in Paul Bowman. Interogating Cultural Studies: Theory, Politics and Practice. London: Pluto Press.

Bennet, Tony. (2015). "Cultural Studies and The Culture Concept" in Cultural Studies, Vol. 29, No. 4, page 546.

Budiman, Manneke. (2014). "Stuart Hall: Gagasan dan Signifikansi" dalam makalah Seminar 100 Tahun Stuart Hall yang diselenggarakan oleh Kajian Budaya dan Media Sekolah Pascasarjana UGM pada tanggal $28 \mathrm{Mei}$ 2014.

Clarke, David. (2016). "Theorising the role of cultural products in cultural diplomacy from a Cultural Studies perspective" in International Journal of Cultural Policy, Vol. 22, No. 2, page 151.

Connell, Kieran \& Hilton, Matthew. (2015). "The working practices of Birmingham's Centre for Contemporary Cultural Studies" in Social History Vol. 40, No. 3, page 289.

Critchley, Simon. (2003). "Why I Love Cultural Studies" in Paul Bowman. Interogating Cultural Studies: Theory, Politics and Practice. London: Pluto Press.

Davis, Helen. (2004). Understanding Stuart Hall. London: Sage.

Faruk. (2014). "Becek is Beautiful: Stuarhalling Pemilu Indonesia 2014" dalam makalah Seminar 100 Tahun Stuart Hall yang diselenggarakan oleh Kajian Budaya dan Media Sekolah Pascasarjana UGM pada tanggal 28 Mei 2014.

Grossberg, Lawrence. (2014). "Cultural Studies and Deleuze-Guattari: A polemic on projects and possiblities" in Cultural Studies, Vol. 28, No. 1, page 18. Hall, Stuart. (2005). "Cultural Studies and 
The Centre: Some Problematics and Problems" in Stuart Hall, et.als. (Eds.) Culture, Media, Language: New York: Routledge.

Harjito. (2014). "Kemandirian Perempuan Jawa dalam Cerita Tradisional", Litera, Jurnal Penelitian Bahasa, Sastra, dan Pengajarannya, Volume 13, Nomor 2, Oktober 2014 hlm. 316-325.

Hebdige, Dick. (2015). "The Worldliness of Cultural Studies" in Cultural Studies, Vol. 29, No. 1, page 33.

Kendall, Gavin. (2001). Understanding Culture. London: Sage.

Milner, Andrew. (2002). Re-Imagining Cultural Studies: The Promises of Cultural Materialism. London: Sage.

McQuillan, Martin. (2003). "The Projection of Cultural Studies" in Paul Bowman. Interogating Cultural Studies: Theory, Politics and Practice. London: Pluto Press.

Morley, David. (2015). "Cultural Studies, Common Sense and Communications: The infra-ordinary, the interdisciplinary and the particular" in Cultural Studies, Vol. 29, No. 1, page 25.

Pickering, Michael. (2008). "Experience and the Social World" in Michael Pickering (Eds.). Research Methods for Cultural Studies. Great Britain: Edinburgh University Press.
Procter, James. (2004). Stuart Hall. New York: Routledge.

Regan, Tom O. (2013). "What matters for cultural studies?" in Inter-Asia Cultural Studies, Vol. 14, No. 3, page 459.

Ryan, Michael. (2010). Cultural Studies: A Practical Introduction. United Kingdom: Willey-Blackwell.

Slack, Jennifer Daryl. (2005). "The Theory and Method of Articulation in Cultural Studies" in David Morley \& KuanHsing Chen. Stuart Hall: Critical Dialogues in Cultural Studies. London and New York: Routledge.

Stacey, Jackie. (2015). "The Unfinished Conversations of Cultural Studies" in Cultural Studies, Vol. 29, No. 1, page 44.

Thukul, Wiji. (2013). Para Jenderal MarahMarah. Jakarta: Tempo.

Turner, Graeme. (2014). "The Mark of Cultural Studies on Communication Research: A perspective from the audience" in Cultural Studies, Vol. 29, No. 1 , page 52 .

Vincent, Hudson. (2013). "Space for Cultural Studies: Conversations with the Centre" in Cultural Studies, Vol. 27, No. 5, page 673.

Wibawa, Sutrisna. (2013). "Nilai Filosofi Jawa dalam Serat Centhini", Litera, Jurnal Penelitian Bahasa, Sastra, dan Pengajarannya, Volume 12, Nomor 2, Oktober 2013 hlm. 328-344. 